\title{
Implementasi Smart Village Product Industrial Activity dalam Pengembangan Petani Jeruk Poncokusumo dalam Mewujudkan Sustainable Development's Society
}

\author{
Heny Kusdiyanti ${ }^{1, *}$, Indra Febrianto ${ }^{2}$, Robby Wijaya ${ }^{3}$ \\ ${ }^{1}$ Faculty of Economics, Universitas Negeri Malang, Semarang Street No 05, Malang, Indonesia \\ ${ }^{2,3}$ Postgraduate Faculty, Universitas Negeri Malang, Semarang Street No 05, Malang, Indonesia \\ ${ }^{1}$ heny.kusdiyanti.fe@um.ac.id $* ;{ }^{2}$ indrafebrianto31@ gmail.com; ${ }^{3}$ robbywijaya1206@gmail.com \\ * corresponding author
}

\section{ARTICLE INFO}

\section{Article history}

Received

Revised

Accepted

Keywords

Eradication of poverty

Orange Farmers

Poncokusumo

Produk industrial activity

Sustainable development's society

\begin{abstract}
This research aims to create the eradication of the poverty model by using smart village product industrial activity that will be implemented in orange farmers in Poncokusumo. This research has done in the planned method include 1) planning, 2) action, 3) evaluation and reflection. Based on data analysis that got by seminar and socialization in Poncokusumo show there are huge potentials in orange products. These products can be used as a competitive product that can be branding for Poncokusumo. This product branding called Poncosweet as a representative of the candy product. By developing this potential product can make smart village product industrial activity toward sustainable development's society in Poncokusumo. The suggestion of this research are all stakeholder should be involved in the developing of the smart village in Poncokusumo.
\end{abstract}

\section{PENDAHULUAN}

Petani Jeruk di Indonesia memiliki kemampuan ekonomi yang tidak sama dengan petani lainnya. Perbedaan tersebut terletak pada masa panen yang tidak mengenal musim. Hal tersebut turut juga dialami oleh petani jeruk Desa Poncokusumo. Masa panen yang tidak mengenal musim memberikan dampak secara langsung terhadap petani baik positif maupun negatif. Pada saat kondisi stok jeruk yang melimpah, berdampak pada rendahnya harga jual dan turunnya permintaan masyarakat, sehingga sering dijumpai jeruk yang membusuk akibat tidak terjual habis. Permasalah semakin diperparah dengan tinggi biaya operasional petani mulai dari pembelian bibit, pupuk, pestisida hingga upah butuh tani. Dengan demikian, diperlukan peran serta masyarakat, organisasi sosial, keagamaan dalam mengatasi masalah petani jeruk manis ini.

Pembukaan ruang yang lebih luas bagi para petani disebabkan oleh pergeseran paradigma, sehinnga partisipasi masyarakat akan lebih luas. Hal ini berimplikasi pada berkembangnya organisasi kemasyarakatakn dalam peningkatan kesejahteraan sosial. Kondisi demikian memberikan konsekuensi logis bagi tempat tempat sosial untuk segera menata sistem tempat dan meningkatkan kompetensi ketempatannya. Dengan demikian, tantangan yang harus dihadapi ladang ke depan adalah pengembangan fungsi ladang itu sendiri, untuk tidak lagi berfungsi sebagai tempat pembuangan jeruk manis saja, tetapi harus menjadi tempat yang mampu menjadi tempat kewirausahaan, yang mampu memberikan tempat prima bagi petani jeruk manis menjadikan manusia produktif yang berdaya dan mandiri minimal untuk dirinya, lebih lanjut diharapkan juga mampu memberdayakan keluarga dan lingkungannya setelah keluar dari sekolah kelak.

Dalam mengelola ladang para petani harus memilih model pendekatan yang tepat sehingga dapat dicapai tujuan utama keberadaan tempat ladang sebagai tempat pemberdayan petani jeruk manis. Peran serta Peguruan Tinggi dianggap penting mengingat rata-rata kemampuan orangtua petani jeruk untuk membiayai anak-anaknya hanya sampai ke jenjang pendidikan SMA. Untuk sampai ke perguruan tinggi secara finansial tidak mampu. Pengalaman menunjukkan ketika seorang petani jeruk ladang tidak dipersiapkan dengan baik untuk dapat hidup mandiri di masyarakat melalui sejumlah keterampilan untuk hidup dan tumbuhnya jiwa 
wirausaha, maka nanti setelah keluar dari sekolah tetap menjadi pengangguran, mengingat lapangan pekerjaan yang disediakan pemerintah maupun swasta jumlahnya masih sangat terbatas. Bahkan, yang membuat miris adalah sebagian dari petani-petani jeruk di ladang, akan kembali menjadi petani musiman yang justru akan membuat ia tidak mempunyai masa depan. Oleh karena itu peran Perguruan Tinggi sebagai bagian dari komponen masyarakat diharapkan bisa membantu mempersiapkan petani jeruk untuk dapat menjalani hidup yang lebih baik.

Berdasarkan identifikasi terhadap permasalahan di atas, diperlukan alternatif solusi yang mampu memberdayakan petani petani jeruk ladang di Kota Malang dengan melakukan kegiatan pengabdian dengan judul Konsep Smart Village With Cycle System Of Product Industrial Activities Sebagai Solusi Pengembangan Petani Jeruk Untuk Mewujudkan Suistainabel Development Of Indonesia.

\section{METODE}

Pelaksanaan pengabdian masyarakat dilakukan dengan metode yang terencana. Berikut tahapan pelaksanaannya:

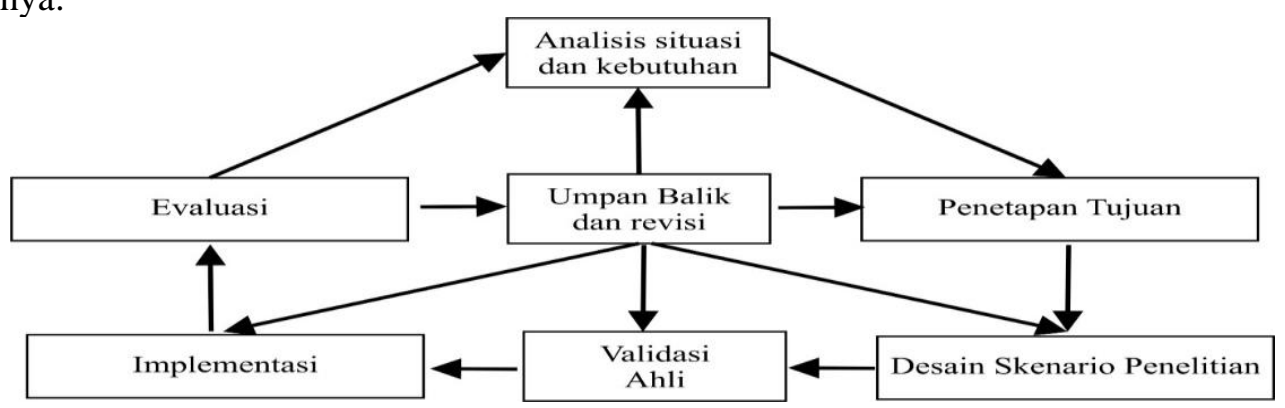

Gambar 3. Diagram Alir Metode Pelaksanaan

Diagram alir diatas dapat dijabarkan sebagai berikut:

\section{A. Analisis Situasi dan Kebutuhan}

Analisis situasi dilakukan untuk mengetahui jumlah dan kondisi petani jeruk Desa Poncokusumo terkini sehingga bisa diperkirakan daftar kebutuhan yang diperlukan saat diadakan pelatihan. Terdapat 60 Petani Jeruk manis dalam satu desa. Dibutuhkan $2 \mathrm{~kg}$ jeruk dan peralatan masak untuk simulasi pembuatan permen jeruk.

\section{B. Penetapan Tujuan}

Tujuan dari pengabdian masyarakat ini adalah untuk memberikan pelatihan pengolahan jeruk menjadi produk bernilai jual yaitu permen jeruk sebagai wujud smart village. Pelatihan ini juga dimaksudkan untuk melatih petani agar bisa menjual jeruk dalam bentuk lain agar memiliki opsi ketika harga jual buah jeruk menurun atau persediaan terlalu melimpah. Dalam jangka panjang, permen jeruk diharapkan bisa menjadi oleh-oleh khas daerah Poncokusumo karena Poncokusumo menjadi salah satu desa wisata di Kabupaten Malang.

\section{Desain Skenario Pelatihan}

Pelatihan dibuat dengan konsep penyuluhan terarah yang mendatangkan pemateri profesional sesuai bidangnya. Pemateri tersebut diantaranya Ahli Boga, Ahli Ekonomi serta Ahli Desain dan Kemasan. Usai pemaparan materi, peserta melakukan uji coba pembuatan permen secara mandiri didampingi oleh masing-masing pemateri dan adanya bentuk kontrol setiap periode untuk melihat perkembangan petani dalam mengelola jeruk.

\section{Validasi Ahli}

Validasi dilakukan untuk mengetahui dan membuktikan bahwa desain dan skenario yang disusun telah sesuai dan terstandar. Validsai dilakukan mulai dari bahan, proses, prosedur, kegiatan, mekanisme produksi agar mampu mencapai hasil yang diinginkan. Validasi dilakukan oleh ahli, diantaranya: 1) menu dan proses produksi oleh Laily Nur Fitriana S.Pd selaku guru Tata Boga, 2) Desain dan Packaging oleh Andreas Syah Pahlevi selaku ketua Asosiasi Design Grafis Indonesia, dan 3) Pembukuan dan Pemasaran oleh Nurudin Zanky S.Pd., M.Pd selaku Dosen Fakultas Ekonomi. 


\section{E. Evaluasi}

Evaluasi dan pembuatan laporan dilakukan diakhir pengabdian masyarakat untuk mengetahui tingkat keberhasilan dari program yang dijalankan. Selain itu, hasil dari evaluasi juga akan digunakan sebagai indikator untuk perbaikan program sehingga proses produksi permen jeruk bisa mengalami peningkatan baik dari sisi kualitas, kuantitas serta manajemennya.

\section{HASIL DAN PEMBAHASAN}

Pelaksanaan pengabdian masyarakat dengan judul Konsep Smart Village With Cycle System Of Product Industrial Activities Sebagai Solusi Pengembangan Petani Jeruk Untuk Mewujudkan Suistainabel Development's Society dilakukan dengan beberapa kegiatan, diantaranya sebagai berikut:

\section{Penyuluhan Manfaat dan Cara Pengolahan Jeruk}

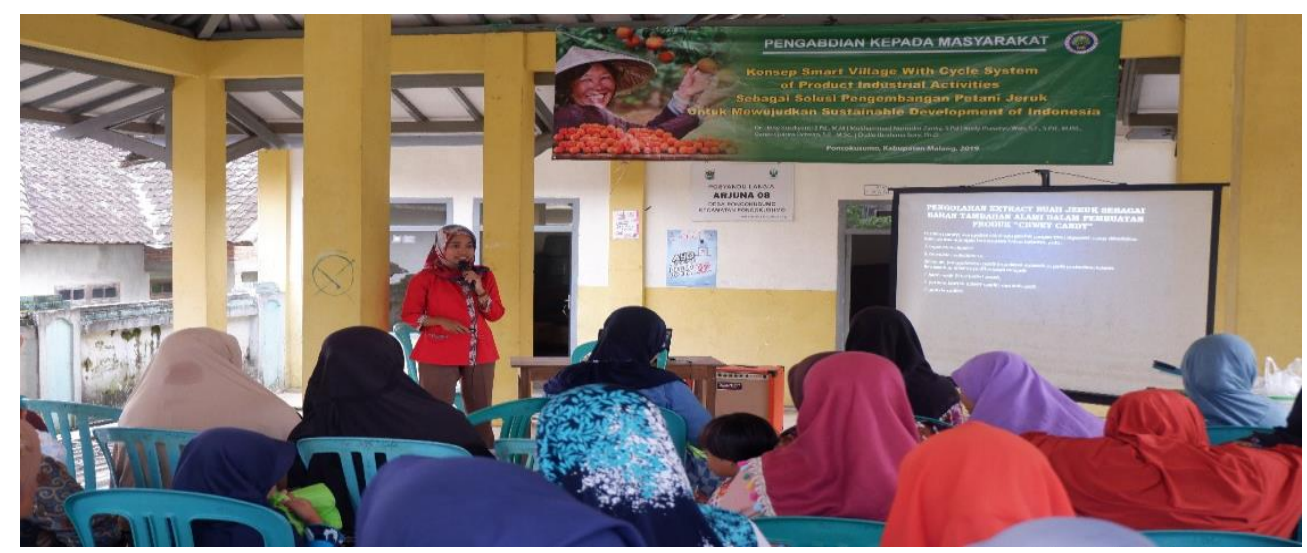

Gambar 4. Penyuluhan Pemanfaatan Jeruk Sebagai Permen

Proses implementasi program diawali dengan penyuluhan pemanfaatan jeruk Desa Poncokusumo menjadi berbagai macam olahan yaang bernilai jual salah satunya adalah permen. Penyuluhan dilakukan oleh Ibu Laili Nur Fitriana S.Pd yang merupakan ahli Tata Boga khususnya dalam bidang pengolahan pangan hasil pertanian. Selain proses pembuatannya yang cukup mudah, permen dipilih karena dapat menjadi produk yang potensial untuk terus dikembangkan dan bisa menjadi produk khas masyarakat setempat, mengingat Poncokusumo masuk di dalam program PONCOWISMOJATU Kabupaten Malang yang membuat Desa Tersebut menjadi salah satu Desa Wisata. Permen nantinya juga akan menjadi produk khas dan oleh-oleh Desa Poncokusumo. Selain permen diminati oleh semua golongan usia terutama anak-anak, permen yang dihasilkan juga memiliki tekstur yang kenyal dengan rasa yang manis dan sedikit asam. Selama proses penyuluhan, masyarakat dan juga petani dibekali berbagai macam bahan dan alat yang diperlukan hingga proses memasak itu selesai. 60 orang peserta terlihat sangat antusias ketika mengikuti penyuluhan yang diberikan. Pengolahan jeruk menjadi permen diharapkan bisa menjadi solusi ketika harga jual jeruk yang terlalu rendah atau saat jumlah panen yang melimpah dan berpotensi banyak jeruk yang membusuk. Solusi inilah yang disambut dengan sangat baik oleh seluruh warga setempat.

\section{Pelatihan Packaging dan Branding}

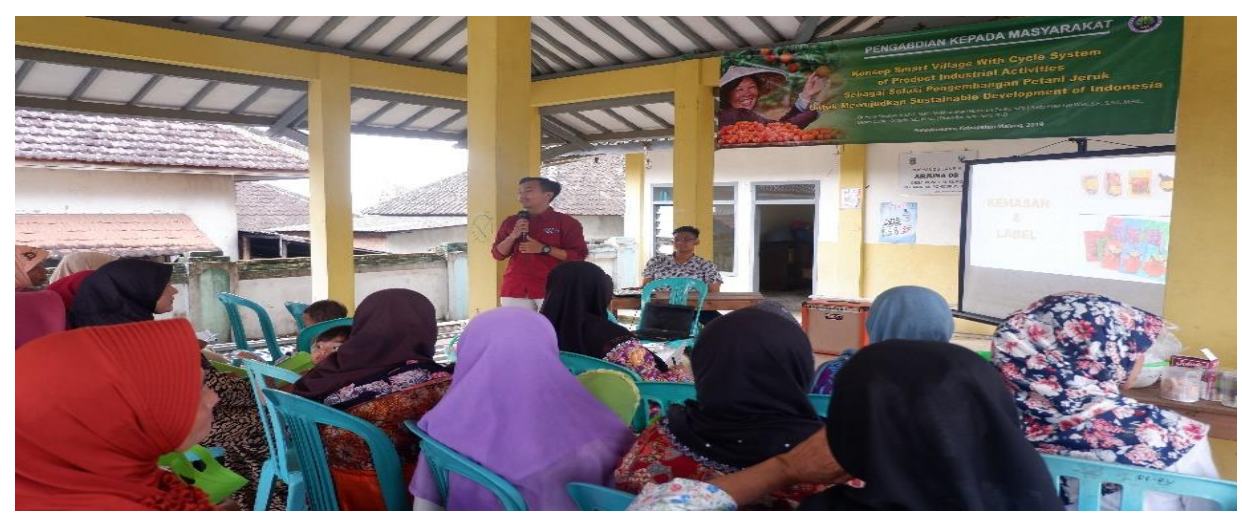

Gambar 6. Pemberian Materi Packaging dan Branding Oleh Ahli 
Di era digital saat ini, packaging dan branding menjadi hal yang sangat penting dalam suatu produk. Materi di berikan secara langsung oleh Ekki Septian Putra S.Pd tentang bagaimana mengemas dan memberikan label pada suatu produk serta penitngnya kemasan terhadap hasil panjualan. Selain produk terlihat lebih meyakinkan, packaging dan branding juga akan meningkatkan hasil penjualan dan memiliki dampak terhadap ekonomi masyarakat setempat. Permen jeruk dikemas dengan desain yang kekinian dan mengikuti tren pasar agar bisa ditrima. Produk tidak hanya dipasarkan di daerah setempat, melainkan juga dimasukan ke tempat oleh-oleh. Disekitar desa poncokusumo memiliki banyak destinasi wisata alam yang salah satunya adalah Gunung Bromo. Tingginya jumlah wisatawan yang masuk setiap harinya, semakin menunjukan tingginya prospek akan usaha dan produk oleh-oleh khas masyarakat sekitar. Sehingga, jeruk tidak hanya di jual dalam wujud buah, melainkan juga produk olahan yang memliki harga jual lebih tinggi dan daya simpan lebih lama. Selain packaging dan branding, petani juga diberikan bekal tentang legalitas usaha seperti BPOM, PIRT dan Halal. Meskipun terkendala pada latar belakang pendidikan yang rendah, namun materi ini tetap penting untuk disampaian dan diajarkan kepada petani secara perlahan.

"Poncoku Sweet" merupakan branding yang diangkat sebagai identitas produk yang memang berasal dari Poncokusumo. Adapun packaging produk dibagi menjadi 2 varian, yaitu premium dan regular yang masing-maisng memiliki segmentasi pasar yang berbeda. Berikut hasil packaging yang diterapkan pada poduk permen jeruk.

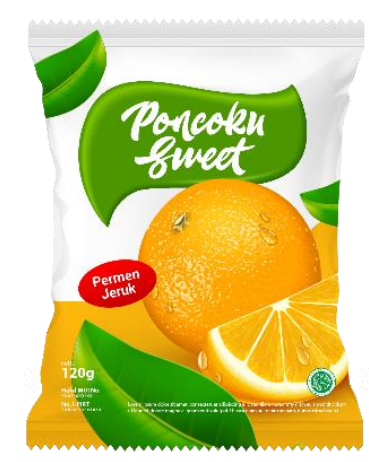

(a)

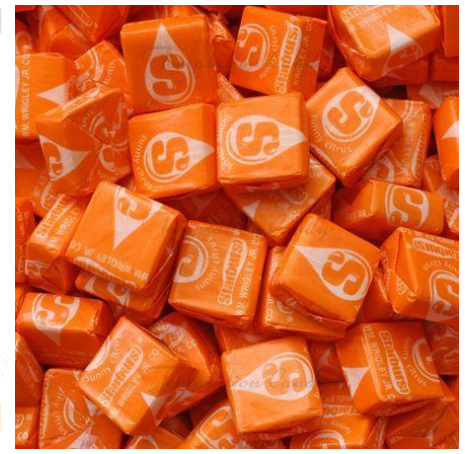

(b)
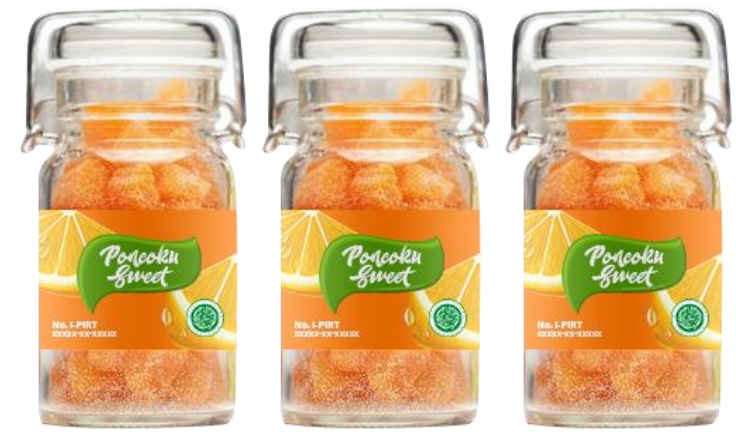

(c)

Gambar 7. (a) Packaging regular, (b) packaging tiap butir permen, (c) packaging premium

\section{Pelatihan Pembukuan Sederhana}

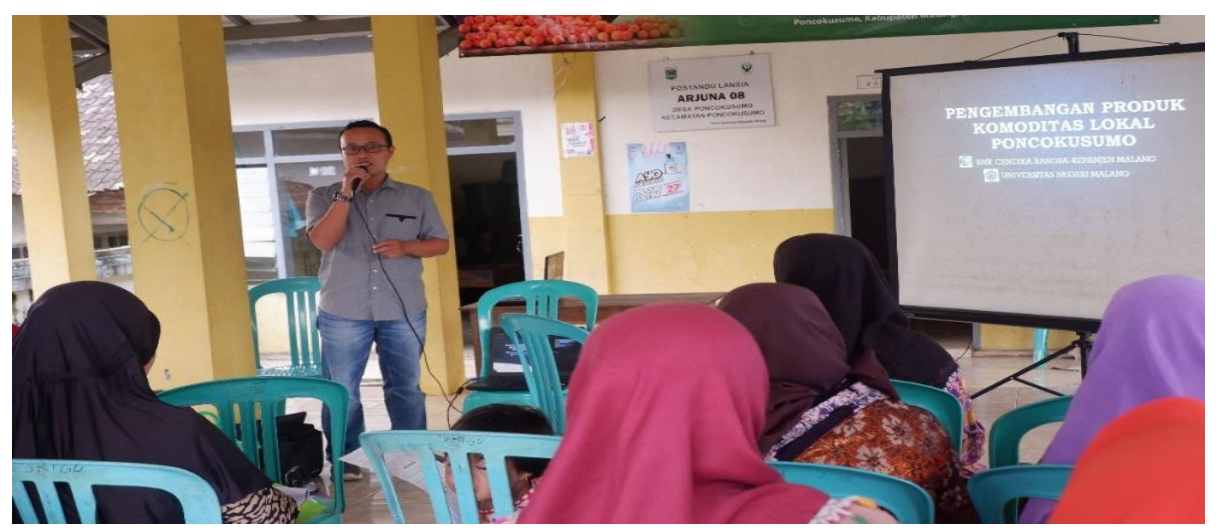

Gambar 8. Penjelasan Materi Pembukuan yang Disampaikan Oleh Dosen Ekonomi 
Pembukuan juga tidak terlepas dari program pengabdian masyarakat yang dijalankan. Materi ini penting untuk diberikan agar dalam proses menjalankan usaha semua uang yang keluar dan masuk dapat terekam dengan baik, maka perlu adanya pembukuan yang dilakukan. Materi ini disampaikan oleh salah satu Dosen Ekonomi, Mokhammad Nurruddin Zanky, S.Pd., M.Pd. Dalam penyampaiannya, materi yang disampaikan hanya terbatas pada pembukuan sederhana meliputi debet, kredit, saldo dan juga rekap laporan akhir setiap akhir bulan. Materi diatas sudah cukup untuk disampaikan pada pelatihan kali ini, agar petani dan juga masyarakat tidak merasa berat dalam menjalankan programnya. Pemateri juga menegaskan jika pembukuan menjadi penting, karena akan merekap semua aktivitas transaksi sehingga semua uang dapat terlaporkan dengan baik dan pastinya bisa mendukung pertembuhan serta perkembangan usaha permen jeruk ini.

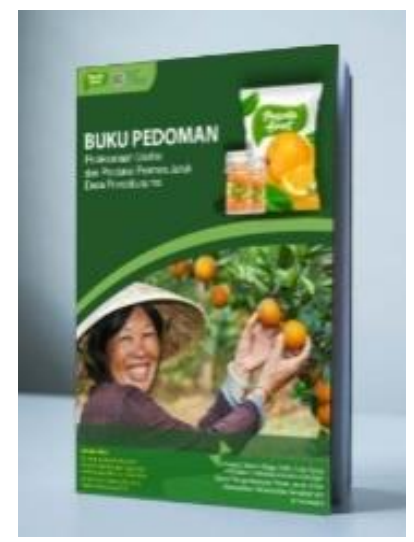

Gambar 9. Buku Panduan Pengabdian Masyarakat Desa Poncokusumo

Agar program pengabdian masyarakat tetap berjalan kedepannya, maka dibutuhkan buku pedoman sebagai buku pendamping menjalakan usaha permen jeruk. Buku pedoman ini difungsikan untuk menjaga kualitas produksi agar tetap sama serta sebagai landasan dasar menjalankan usaha agar tetap terarah. Adapun buku pedoman yang dibuat berisikan tentang alat dan bahan yang dibutuhkan, resep permen jeruk, daftar legalitas usaha yang dibutuhkan dan strategi pemasaran.

\section{KESIMPULAN DAN SARAN}

\section{Kesimpulan}

Berdasarakan kegiatan pengabdian yang telah dilakukan di Desa Poncokusumo didapatkan terdapat perubahan pemahaman masyarakat tentang pengelolahan jeruk agar lebih berdaya guna. Masyarakat telah memahami penggolahan jeruk menjadi permen yang nantinya akan menjadi salah satu usaha masyarakar Desa Poncokusumo untuk membentuk UKM-UKM baru di desa ini sebagai salah satu upaya untuk mewujudkan Sustainable Development of Indonesia.

\section{Saran}

Demi terciptanya masyarakat yang mandiri dan memiliki produk olahan khas Desa setempat, makan kedepannya telah disusun program-program yang akan diberikan untuk menyempurnakan usaha yang telah dibentuk. Adapun program-program tersebut adalah sebagai berikut:

a) Pelatihan pengurusan legalitas usaha.

b) Pelatihan pembuatan permen dalam skala besar menggunakan mesin.

c) Kunjungan ke Balai Penelitian Tanaman Jeruk dan Buah Suptropika (BALITJESTRO) untuk meningkatkan kualitas dan produktivitas tanaman jeruk Desa Poncokusumo.

d) Pelatihan Digital Marketing untuk PKK sebagai pelaksanan usaha masyarakat setempat.

\section{DAFTAR PUSTAKA}

Hendrati Dwi Mulyaningsih. 2014. "Initial Conceptual Model of Knowledge-Based Social Innovation.” World Applied Sciences Journal 30: 256-62.

Bengtsson, Mariette. 2016. "How to Plan and Perform a Qualitative Study Using Content Analysis." NursingPlus Open 2: 8-14. http://dx.doi.org/10.1016/j.npls.2016.01.001. 
Boulven, Mohd Adib et al. 2018. "Model of Islamic Social Entrepreneurship: A Study on Successful Muslim Social Entrepreneur in Malaysia." MATEC Web of Conferences 150: 10-13.

"Kontribusi UMKM Terhadap PDB 2019 Diproyeksi Tumbuh 5\% - Ekonomi Bisnis.Com." https://ekonomi.bisnis.com/read/20190109/12/876943/kontribusi-umkm-terhadap-pdb-2019diproyeksi-tumbuh-5 (January 9, 2020).

Lin, Ruey Fa, Ho Don Yan, and Chi Yin Wu. 2018. "Social Entrepreneurship and Charismatic Leadership: Master Cheng Yen and Tzu Chi Foundation." International Journal of Innovation and Regional Development 8(2): 136.

Pathak, Resham Raj, Bishwash Raj Poudel, and Paras Education Acharya. 2018. "Social Enterprise and Social Entrepreneurship: Conceptual Clarity and Implication in Nepalese Context.” NCC Journal 3(1): 143-52.

Pujiati, Anik, and R. Retariandalas. 2019. "Utilization of Domestic Waste for Bar Soap and Enzyme Cleanner (Ecoenzyme) [Pemanfaatan Limbah Rumah Tangga Untuk Pembuatan Sabun Batang Dan Pembersih Serbaguna (Ecoenzym)]." Proceeding of Community Development 2: 777.

Raihan, Nur, Che Nawi, Mohd Mursyid Arshad, and Steven Eric Krauss. 2018. "Social Entrepreneur as Career: Why It Attracts Youth in Malaysia? Religiosity View Project The Experts' Opinion: Defining Success in Entrepreneur Development Programmes View Project.” http://dx.doi.org/10.6007/IJARBSS/v8-i6/4177 (January 9, 2020).

Ramadani, Veland, Léo Paul Dana, Shqipe Gërguri-Rashiti, and Vanessa Ratten. 2016. "Entrepreneurship and Management in an Islamic Context." Entrepreneurship and Management in an Islamic Context (September): 1-248.

Ramoglou, Stratos, - Stelios, and C Zyglidopoulos. "The Constructivist View of Entrepreneurial Opportunities: A Critical Analysis."

Ramoglou, Stratos, and Eric W K Tsang. 2016. "A REALIST PERSPECTIVE OF ENTREPRENEURSHIP: OPPORTUNITIES AS PROPENSITIES.” $Q$ Academy of Management Review 41(3): 410-34. http://dx.doi.org/10.5465/amr.2014.0281 (January 9, 2020).

Schaltegger, Stefan, Florian Lüdeke-Freund, and Erik G Hansen. 2016. "Business Models for Sustainability: A Co-Evolutionary Analysis of Sustainable Entrepreneurship, Innovation, and Transformation." Organization \& Environment 29(3): 264-89.

Short, Jeremy C, Todd W Moss, and G T Lumpkin. 2009. "RESEARCH IN SOCIAL ENTREPRENEURSHIP: PAST CONTRIBUTIONS AND FUTURE OPPORTUNITIES.” Strategic Entrepreneurship Journal Strat. Entrepreneurship J 3: 161-94. www.interscience.wiley.com (January 9, 2020).

Wirtz, Bernd W, Adriano Pistoia, Sebastian Ullrich, and Vincent G € Ottel. 2015. "Business Models: Origin, Development and Future Research Perspectives." http://dx.doi.org/10.1016/j.lrp.2015.04.001 (January 9, 2020). 